\title{
Research on the Countermeasures for Supervision of Individual Workshops of Food Processing and Production in China
}

\author{
Jia Zuo \\ Party School of the Communist Party of China in Liaoning Province \\ Shenyang, China
}

\begin{abstract}
Relying on a large platform of food safety and supervision, based on the study of the status quo and existing problems in the production and processing supervision of individual food workshops in China, this paper proposes some countermeasures and suggestions on how to strengthen supervision on individual food production and processing workshops in China and guide its healthy development.
\end{abstract}

Keywords—food processing; individual workshop; food safety; supervision

\section{INTRODUCTION}

The individual workshops have existed since ancient times. A variety of Chinese traditional foods are inherited by individual workshops. The food production individual workshops are also very common in the food market of China. During the transformation of modernization, the individual workshops are not only under the pressure of industrialization, mechanization and large-scale production, and food safety risks, but also assume the mission to maintain the livelihood of some low-income people and meet the multi-level needs of consumers. The situation of individual workshops is: "one end is connected with safety, one is connected with people's livelihood; one is connected with hidden dangers, and one is connected with employment". Thus it can be seen that the supervision on the individual workshops is not a small and easy matter.

\section{THE STATUS QUO OF INDIVIDUAL WORKSHOPS OF FOOD PROCESSING AND PRODUCTION IN CHINA}

\section{A. Individual Workshops Are Generally Small in Size, Large in Quantity, and Widely Distributed}

China has a vast territory and a large population. Mary individual workshops for food production and processing are distributed in urban and rural areas, and most are formed by husband-and-wife family workshop. Some individual workshops are in the form of "having stores in front and factories behind". Foods processed by individual workshops are sold directly in the shop in front of factory. Other individual workshops are not in this form. They process the foods in their workshop, and then transport the processed foods into circulation. Such individual workshops are often hidden in the common family. They are not easy to be found in case of no obvious individual workshop signs, and the supervision is more difficult.

\section{B. The Health Environment of Many Individual Workshops Is Not up to the Standard}

Characterized by low investment and small scale, these individual workshops will mainly consider the price when choosing the production and business sites. Most of individual workshops are located in area where poor people live mostly, and they will rent the bungalows or the houses that can be used for living or operation down the street. In such a large environment, the workshops themselves are in a mixed environment, coupled with the fact that the individual workshops often produce some traditional foods with low costs, so producers tend to attach great importance to the benefits from food production without considering the sanitary conditions of individual workshops.

\section{There Is No Uniform Standard for Food Raw Materials, Additives and Packaging}

First, the material source of the food individual workshops exist hidden danger. Environmental pollution is serious in some area of China. The discharge of industrial waste gas and water brings different degrees of pollution to the atmosphere and water resources. The crops may be suffered a certain level of pollution during the growth, together with the use of pesticides and other chemicals in the process of agricultural production, if not effectively and reasonably cleaned or decomposed, they will cause an irreversible damage to the masses, especially the old and the children. If the individual workshop producers fail to check the raw materials and do necessary treatment, these contaminated or residual pesticidecontaining ingredients will be processed into toxic and hazardous foods to enter the market.

Second, the situation that the individual workshops randomly use food additives is serious. Individual workshops have a profound history background, and mainly process some traditional low cost foods. Many foods produced by individual workshops are unique, which inherit several processing techniques of many generations. Some workshops use a secret recipe, in fact, they add some special or even harmful additives 
that do not meet the national standards and make the food taste unusual, thus deceiving the consumers.

Third, many foods produced by the individual workshops have no reliable packaging. Most of the foods produced by individual workshops are quickly put into sales and circulation links, so most of them are simply packed or not packed at all. It is difficult to determine the specific storage life of such foods, and also hard for consumers to figure out the exact date of production when they receive it. There is no necessary storage means for the food in this process. Since there is no uniform standard of packaging, what the consumers have bought is a kind of food that does not have the date of production, storage life and raw material composition. How can people eat without worry? What's more, in terms of these packed foods, the owners of individual workshops usually wholesale cheaper plastic packing bags to reduce costs. These cheap plastic bags are usually not dedicated for food. Some freshly baked foods are at high temperature, and these nonedible packing bags will produce substances that are harmful to human health at high temperatures. Or some packing bags themselves are in a poor hygiene and carry bacteria and toxic and harmful substances, which are also harmful to human health in case of being used for containing foods.

\section{PROBLEMS IN SUPERVISION OF INDIVIDUAL WORKSHOPS OF FOOD PRODUCTION AND PROCESSING IN CHINA}

\section{A. There Is a Deviation between Supervision Mechanisms, Supervision Capabilities and Supervision Requirements}

The Food Safety Law and relevant central files all require that local governments must assume overall responsibility in terms of food safety. However, the authority qualifications are concentrated in the provincial, municipal, and district-level (county-level) government, and basic township government has not attached importance to food safety supervision. The statutory duties of functional supervision above district level and county level are relatively perfect. Their food safety work is relatively systematic, and has a certain cohesion and continuity. The statutory duties of territorial administration of grassroots government below the country level are not clear. The relevant supervisory team and full-time staff at the grassroots level are insufficient, and the staff mobility is large, and the funds for primary food safety are relatively low. The township (community) technical service system is incomplete, and some jurisdictions have not incorporated food safety into the performance evaluation of grassroots governments. Grassroots governments and grassroots leading cadres have paid less attention to food safety in their jurisdictions.

\section{B. The Division of Labor in the Supervision Department of Individual Workshop Is Not Clear}

In recent years, the problems exposed in the supervision of individual workshops have not only occurred to the individual workshop itself, but also to some law-executors. The regulation and supervision on individual workshops usually involve various departments such as industry and commerce department, quality supervision department, agriculture department and so on. In terms of supervision, there are power conflicts in some aspects, and there are some vacant powers in some respects. As a result, some problems are not managed, and other problems are handled by supervisor in case of falling over one another.

Taking poison bean sprout event as an example, in the law enforcement work, various functional departments have different opinions on how to supervise bean sprouts and thoroughly eliminate the hidden danger of poisonous bean sprouts. The responsibility of the industry and commerce department is to manage the market from microcosmic aspects, involving registration and daily supervision for privately or individually-owned business. However, the fact that some individual workshops have not obtained food production license in the field of food production and still operated without license actually exists, and the behaviors of above individual workshops are all punished as unlicensed business activities, which will be unscientific. The industrial and commercial bureau believes that the Bureau of Quality Supervision should bear the supervisory responsibilities within the scope of food production. The quality supervision department regards the bean sprout as primary agricultural products, and believes that this problem is not in the scope of product quality law adjustment, and then throws the blame on agriculture department. The agricultural sector manifests that bean sprouts are the products of processed agricultural products by comparing with the primary products and process products and believes that bean sprouts not comply with the description of primary agricultural products in Agricultural Product Quality Security Law, therefore, they think that this affair is not within their powers and rights. Every department has their reasons. However, should we sit by and let the lawbreakers act recklessly or wildly when facing with such problems? Therefore, the equitable distribution for responsibility is also the problems that cannot be ignored for lawmaker and law-executor.

\section{The Long-term Mechanism of Preventing and Treating Emergencies Has Not Been Established}

Food safety emergencies are directly related to the health and life safety of the majority of consumer groups, and are the focus of society and media at the same time. After the occurrence of food safety emergency in individual workshops, the leaders tend to attach great importance to it and allocate sufficient resources, which make it easy to effectively curb the development of emergencies and quickly appease the situation. However, related risk early warning and retrospective rectification need a large resource investment, and it is often difficult to reflect effects in a short time, so the resource investment is relatively inadequate. Currently, food safety problems are basically dealt with in this way: inundant food safety problems- crackdown- temporary relief of safety problems- being rampant again-crackdown again-temporary relief of safety problems- being rampant again-crackdown again. Food safety emergencies repeatedly occurred in different ways such as "resurgence", "comeback" and "making only superficial changes". The lack of specification and continuous crackdown on counterfeit and shoddy goods is difficult to fundamentally solve the problem of food safety. 


\section{COUNTERMEASURE AND SUGGESTION ON IMPROVING THE SUPERVISION AND MANAGEMENT OF INDIVIDUAL WORKSHOPS OF FOOD PRODUCTION AND PROCESSING IN CHINA}

\section{A. Strengthen Related Legislation}

We need to develop more detailed standards to guide the supervision of individual workshops in the future. The Food Safety Law, which was revised in 2015, has been dubbed by the media as "the strictest food safety law in history", and it has increased and improved many legal systems. However, with regard to the specific management measures for food production and processing workshops and food vendors, the law chose to empower the rights to the local again. In August 2016, China Food and Drug Administration issued the Implementation Opinions on Comprehensively Strengthening the Legal Construction of Food and Drug System Supervision. It has emphasized that we should "actively promote local food and drug regulatory legislation, encourage and support local food and drug regulatory authorities to participate in the formulation and revision of local rules and regulations concerning food and drug supervision, and guide local government to accelerate the completion of local food safety legislation tasks for individual food production and processing workshops, food vendors and small restaurants".

Supervision should be based on law. We should formulate food safety supervision and management method for individual workshops that are in line with the actual situation as soon as possible. The method must clearly stipulate the responsibilities of individual food workshops and regulators, supervisory procedures and accountability of regulatory responsibilities, and it also should be operable. In addition, we must establish and improve the corresponding regulatory standards, further perfect the production and operation standards of individual food workshops, and make laws and regulations operable while ensuing food safety. In the meantime, we must establish a monitoring standard for individual food workshops through research, so that the supervision department and the supervisor have clear standards to comply with, and have laws to abide by.

\section{B. Regulatory Rights and Liabilities Are Transferred to a Lower Level and Improve Institutional Mechanisms}

We will delegate the power of food supervision to the township referring to the national fundamental policies that the local government is responsible for food safety in the region. In view of the lack of a complete and independent top-down vertical management system in the field of food safety in China, the organization and appointment of food safety supervision bodies at all levels will be decided by the local government at each level. Therefore, we must fully exert the role of the local food safety management system, and the government at all levels should be responsible for the supervision of food safety within the jurisdiction and implement the executive accountability system. The general principle of the Food Safety Law has specified the local government's overall responsibility in the supervision of food safety within the jurisdiction, but the primary responsibility of government at the local grass roots below the county level is not prominent enough.

Besides, the ideal solution to completely solve the problems of repeated institution and blind spots in the management is to fully integrate the food safety management organs distributed in various departments and place them in an independent food safety management organ. This solution is in line with the international trend, but the operation inertia and equity allocation of various departments have a great impact on the existing administrative system, so the reform is more difficult. The township level is the frontline position of food safety supervision. Human rights and powers are relatively simple, and office and law enforcement sites are more concentrated, and the integration of various regulatory functions is more feasible.

During the decentralization of food safety supervision power and responsibility in individual workshops into the township, we should improve and promote the relevant rules and regulations as soon as possible, incorporate food safety into the performance evaluation of grassroots township governments, and promote the implementation of the system of "government taking charge responsibility, department supervision responsibility, production subject responsibility, and social public supervision responsibility" for food safety. In the process of the decentralization of power and responsibility, the township government should be granted a certain punishment function while authorizing propaganda and mobilization, data statistics, and assistance management, and the assessment and evaluation should be organically integrated with the performance of grassroots government's food safety guarantee.

\section{Perfect Market Access Review System}

On the basis of adhering to the unity of the whole, individual equality should be maintained. The government should not suppress the daily operation of individual food workshops and the policy orientation of individual workshop's gradual upgrading to enterprise, and give some assistance instead. Small and medium-sized workshops are in bad situation in many aspects in the market competition relative to the enterprises above designated size, if there is no government policy inclination and support, it is easy to cause the situation that enterprise above designated size monopolizes the market, thus destroying the rational distribution of the food industry, weakening the development potential of the food industry and harming the interests of consumers.

According to the characteristics of different food industries, through reasonable administrative guidance, the individual workshop should promote development of the industry while ensuring food safety. Along with the demand of market and the transformation and upgrading of industry development, some individual workshops introduce advanced equipment, facilities and technologies, improve the environmental conditions for production and processing, take the road of scale production and modern management, and finally realize the rational allocation of scale food production and dotted production and processing sites of individual workshops. Large enterprises and small and medium-sized enterprises 
complement each other to carry forward the traditional diet culture and take into account the actual needs of the various consumer groups while ensuring the prosperity and development of the food industry.

In order to perfect the market access examination system that individual workshop is to upgrade to small enterprise, we should increase the examination and evaluation of food safety laws and regulations, including enterprise legal entity and quality leaders, and strengthen the core team's high awareness of food safety. What's more, for some situation that individual workshops rely on consulting companies to forge information and employ the "writer" to temporarily act inspector to cope with the market access verification, we should file the data including inspectors' ID numbers and photographs online, so as to prevent the "writer" to "deal with" some situation.

\section{Combine "Classified Supervision" and "Orderly Increase"}

Adhering to the principle of "good management and convenience for the people, safety and efficiency", based on the actual economic and social development within the jurisdiction, we must fully investigate and ascertain the basic conditions of the small workshops within the jurisdiction, and then distinguish the causes and objects by classified supervision. In terms of market access, we must firmly ban those individual workshops that abuse food additives, produce counterfeit and shoddy food, and maliciously use nonfood substances, and distinguish those individual workshops that have gradually strengthened their awareness of food safety and quality, use characteristic raw materials and traditional crafts, have fixed sales areas, and can basically control its risk: first, some individual workshops that are typical and have relatively good foundation must make quality commitments to the society, accept social supervision, and play a demonstration role. Second, we must adopt various modes, such as regional rectification, stock cooperation, centralized production, and professional cooperation, to guide the individual workshop and small enterprise to become the biggest and strongest one and developed normatively. Third, We should combine blocking and easing and carry out dynamic management to promote the individual workshops with development prospect to move towards to food enterprises.

\section{E. Combine "Regulation and Ban" and "Persuasion and Helping”}

While regulating and banning the illegal individual workshops, we have intensified to dredge and help the lawabiding individual workshops: first, we should do a good job in propaganda and mobilization, vigorously publicize the national food safety policy and local food safety rules and regulations to individual workshops. Taking typical food quality safety accidents and punishment cases as a warning, we should guide the individual workshops to firmly establish the awareness of "the first responsible person". Second, we should encourage and guide individual food workshops to establish regulations and establish systems, to strictly follow the operational procedures for production and processing, to use system to standardize the various links, key points and procedures of production and sale, so as to ensure food quality and safety. Third, we should guide small workshops to establish three systems, namely, production environmental hygiene management system, purchase and sale verification system of raw materials and quality safety responsibility system, and record the procurement of raw and auxiliary materials and product sales in detail, so that the sources of procurement and sales flow can be checked from both directions. Fourth, for traditional foods with regional characteristics and cultural carriers, we should guide the individual workshop industry association to unite the scientific research institutions to carry out $\mathrm{R} \& \mathrm{D}$ of scientific and technological projects, so as to form specialty products and geographical indication products, and to promote industrial upgrading within the jurisdiction.

\section{CONCLUSION}

In China, individual workshops are generally small in size, large in quantity, and widely distributed. To solve the problems in supervision of individual workshops of food production and processing in China, we must strengthen related legislation, improve institutional mechanisms, and perfect market access review system.

\section{REFERENCES}

[1] Huang Yiwu. Study on the Construction of Food Safety Supervision and Management System in Catering Industry in Shenzhen [D]. Tianjin University 2010.

[2] Zhang Miao, Li Xiexin, Zhang Zhenyu, Jia Hongfeng. On Food Safety in the Catering Industry and Problem-Tackling Strategies [J]. Journal of Sichuan Higher Institute of Cuisine. 2011 (03).

[3] Lin Cuiping. Study on Detection Method of LC-MS/MS of Heterocyclic Aromatic Amines in Meat Products [D]. Tianjin University of Science\&Technology 2012.

[4] Liu Huicui. Analysis of Formation of Advanced Glycationend Products during Processing and Storage of Fried Foods and Its Inhibition [D]. Northwest A\&F University 2014.

[5] Jiang Sanqun. Research on the Change Rules and Influencing Factors of Quality and Harmful Substances in Mutton Shashlik Baking [D]. Xinjiang Agricultural University 2014.

[6] Mei Jingbo. Study on Formation Rule and Control Technique of Heterocyclic Aromatic Amines in Meat Processing [D]. Tianjin University of Science\&Technology 2012.

[7] Wan Kehui. Study on Formation and Control of Heterocyclic Aromatic Amines in Beef Jerky Products [D]. Nanjing Agricultural University 2013.

[8] Cao Haiwei. Study on the Determination of Hazardous Substance Residues in Food by High-performance Liquid Chromatography-mass Spectrometry [D]. Jilin University 2014

[9] Pan Han. Study on the Formation Mechanism of norharman and harman in Braised Pork with Soy Sauce [D]. Chinese Academy of Agricultural Sciences 2014.

[10] Wang Hui. Study on the Application of Liquid Chromatography Tandem Mass Spectrometry in the Analysis of Toxic and Harmful Substances in Food [D]. Hunan University 2013.

[11] Zhu Yunlong, Liu Yan, Ma Jingjie. On the Safety Management of Food and Beverage $[\mathrm{J}]$. Culinary Science Journal of Yangzhou University. 2010(04).

[12] Wei Ming, Tan Lifeng, Li Yanping. Study on the Application of HACCP System in Food Safety Management in University Canteens [J]. Occupation and Health. 2010 (21). 
[13] Xu Munong. Research on Food Safety in China's Catering Industry [J]. Educational Science \& Culture Magazine (The first ten-day journal). 2010(08).

[14] Chen Liping, Pan Xiaochuan, Shi Fuli. Investigation on the Awareness of Food Quantitative Classification Management among Food Catering Personnnel in Haidian District, Beijing [J]. Chinese Journal of Health Inspection. 2010(03) .

[15] Wen Zhonglei. Analysis on Health Supervision Status Quo of Restaurant Industries in Small and Medium-sized Cities [J]. Journal of Yueyang Vocational Technical College. 2010(02).

[16] Wang Yingiie, Ouyang Dan. Study on Building Catering Industry Food Safety Supervision System [J]. World Standardization \& Quality Management. 2009(10).

[17] Zhu Meifang. Discussion on the Application and Experience of " $5 \mathrm{~s}$ Method" Management in Catering Industry [J]. Chinese Journal of Preventive Medicine. 2009(06). 